\title{
Early experience with hand continuous passive motion
}

\author{
Steve Morris MD MSc FRCSC, Arnis Freiberg MD FRCSC FACS, Leonard Harris MD MSc \\ Division of Plastic Surgery, Toronto Western Hospital, University of Toronto, Toronto, Ontario, \\ University of Alberta, Edmonton, Alberta
}

\begin{abstract}
S Morris, A Freiberg, L Harris. Early experience with hand continuous passive motion. Can J Plast Surg 1993;1(1):19-23. Clinical experience with continuous passive motion (CPM) has increased in recent years. However, little information is available in the literature of objective evaluation of the results obtained using this treatment modality. The purpose of this study was to review both the indications for hand CPM at the Toronto Western Hospital, Toronto, Ontario, and the course and the outcome of the patients treated. Between 1984 and 1989 the Mobilimb H1 CPM was used on 43 patients for a mean period of $39 \pm 6$ days (mean total hours of CPM $741 \pm 84 \mathrm{~h}$ ). Indications for hand CPM included hand trauma, capsulectomy and tenolysis and other hand conditions. Mean follow-up was $32 \pm 3$ months. Overall, hand CPM was well tolerated and highly effective in relieving hand pain and increasing active and passive range of motion. Compliance was excellent.
\end{abstract}

Key Words: Continuous passive motion (CPM), Hand surgery, Indications, Outcome, Patient compliance

\section{Expérience préliminaire avec mouvement passif continu de la main}

\begin{abstract}
RÉSUMÉ: L'expérience clinique portant sur le mouvement passif continu (MPC) n'a cessé de s'étendre au cours des dernières années. La littérature renferme cependant peu de renseignements sur l'évaluation objective des résultats obtenus à l'aide de cette modalité thérapeutique. Le but de la présente étude a été de passer en revue tant les indications du MPC de la main au Toronto Western Hospital de Toronto, en Ontario, que l'évolution et l'issue du traitement chez les patients. Entre 1984 et 1989, le MPC Mobilimb H1 a été utilisé chez 43 patients durant une période moyenne de 396 jours (nombre d'heures totales moyen de MPC 7414 heures). Les indications de cette modalité thérapeutique incluaient: traumatisme de la main, capsulectomie, ténolyse et autres problèmes de la main. La période de suivi moyenne a été de 323 mois.a De façon globale, le MPC de la main a été bien toléré et très efficace pour le soulagement de la douleur et l'augmentation de l'amplitude du mouvement actif et passif. L'observance au traitement a été excellente.
\end{abstract}

S ince the pioneering laboratory research by Salter (1-5) on the effects of continuous passive motion on the healing and regeneration of articular cartilage, the clinical applications of continuous passive motion (CPM) have broadened to include the knee, hip, elbow, shoulder and temporomandibular joints (6-11). Recently, interest has steadily increased in the use of hand CPM (Figure 1). Therapists and surgeons have been reluctant to employ this modality and there is a paucity of information in the literature reporting results obtained using hand CPM. Several authors have reported on experience with isolated indications for hand CPM (12-17). No long term studies are available, however, to document the course and outcome of patients treated with hand CPM. This review studies the indications, course and outcome in patients treated with hand CPM used as an adjunct to hand surgery. The majority of these cases represent salvage situations in which hand CPM was used in the presence of devastating

Correspondence and reprints: Dr A Freiberg, Head Division of Plastic Surgery, Toronto Western Hospital, 399 Bathurst Street, ECW 4-034, Toronto, Ontario M5T 2S8, Telephone (416) 369-5691, Fax (4I6) $369-5297$ hand injuries. A number of the reconstructive cases would not have been attempted had hand CPM not been available.

\section{MATERIALS AND METHODS}

All patients who were placed on hand CPM at Toronto Western Hospital between 1984 and 1989, and who were available for follow-up examination and interview, were included in the study. Of a total of 43 patients, 36 were available for review, while seven were lost to follow-up. These 36 patients were interviewed and a standard questionnaire was administered. As well, all inpatient, outpatient and therapy charts were reviewed. Hand dominance, injured hand, type of injury, age, sex, type of surgery, duration and method of CPM use and overall outcome were assessed. Each patient was asked to complete an assessment of pain and outcome according to a visual analogue scale. This test was administered by a person other than the patient's surgeon or therapist. The patient was asked to mark a cross on a $10 \mathrm{~cm}$ line to indicate their assessment of overall outcome, function, pain and satisfaction $(0=$ low or unfavourable; $10=$ high or favourable $)$. This test was selected to determine in an unbiased manner the patient's subjective impression of the CPM device. In all 43 


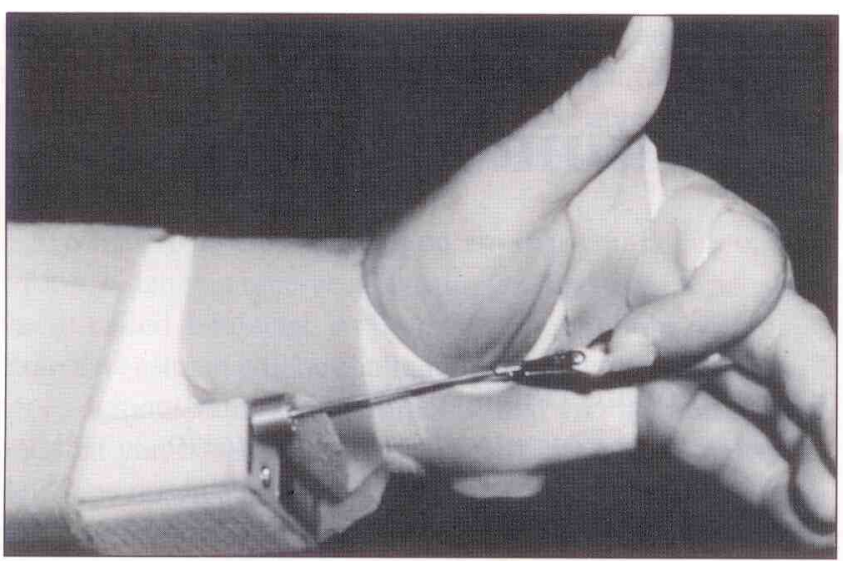

Figure 1) The Mobilimb HI continuous passive motion (CPM) unit, in situ

patients the Mobilimb CPM unit was used (H1 or $\mathrm{H} 2$ models, Toronto Medical Corporation, Pickering, Ontario). All surgical procedures were performed or directly supervised by the senior author (AF).

Postoperatively, the hand CPM unit was applied within the first $24 \mathrm{~h}$, often in the operating room or recovery room. The patients were instructed on application, removal and care of the CPM device prior to discharge from hospital. All patients were advised to use the hand CPM device $23 \mathrm{~h}$ per day. The Mobilimb CPM unit was used for periods of 11 to 140 days ( $39 \pm 6$ days; mean \pm SEM), and was removed when the hand active range of motion (ROM) matched that achieved on the CPM unit. If the ROM was not maintained during the first week post-CPM, hand CPM was restarted. Frequent follow-up was arranged when possible in the hand surgery clinic and hand therapy unit. A hand therapist supervised all aspects of hand CPM use. ROM results are herein reported according to the Strickland formula for proximal (PIP) and distal interphalangeal (DIP) joint motion and as total active motion (TAM) (18). The Mobilimb CPM unit was chosen for use in these patients because it is durable, lightweight and well accepted by patients.

Statistical analysis of the data was performed with a Macintosh SE microcomputer. Paired and unpaired $t$ tests (two-tailed) were used to compare two means. Multiple comparisons of means were performed using one-way analysis of variance (ANOVA) or two-way ANOVA. The level of probability accepted as significant was $\mathrm{P}<0.05$. Variation of means is reported as standard error unless otherwise specified.

\section{RESULTS}

Indications for the use of hand CPM were divided into three groups. Group A: trauma (total nine patients, 16 digits) severe lacerations $(n=3)$, crush injuries $(n=4)$, fractures $(n=1)$ and joint injuries (1); Group B: reconstructive (total 22 patients, 26 digits) metacarpal phalangeal (MCP) arthroplasty $(n=5)$, extensor tenolysis and proximal interphalangeal (PIP) joint capsulectomy $(n=17)$; and Group C: miscellaneous (total five patients, nine digits) reflex sympathetic dystrophy
TABLE 1: Duration of hand CPM unit use

\begin{tabular}{cccc}
\hline & $\begin{array}{c}\text { Acute } \\
\text { Group A }\end{array}$ & $\begin{array}{c}\text { Elective } \\
\text { Group B }\end{array}$ & Total \\
\hline $\begin{array}{c}\text { Duration (days) } \\
\text { (range) }\end{array}$ & $56 \pm 15$ & $33 \pm 5$ & $39 \pm 6$ \\
Time/day & 14 to 140$)$ & $(11$ to 96$)$ & $(11$ to 140$)$ \\
(range) & $(10 \pm 1$ & $19 \pm 1$ & $19 \pm 1$ \\
Total hours & $1008 \pm 222$ & $(8$ to 24$)$ & $(8$ to 24$)$ \\
(range) & $(196$ to 2160$)$ & $(152$ to 1440$)$ & $(152$ to 2160$)$ \\
\hline
\end{tabular}

Values are presented as means \pm standard error

TABLE 2: Removal of CPM machine by patient during therapy period

\begin{tabular}{lccc}
\hline Removed/day & $\begin{array}{c}\text { Acute } \\
\text { Group A }\end{array}$ & $\begin{array}{c}\text { Elective } \\
\text { Group B }\end{array}$ & Total \\
\hline 0 to 2 & 5 & 7 & 12 \\
3 to 5 & 4 & 11 & 15 \\
$>5$ & 0 & 4 & 4 \\
\hline
\end{tabular}

No significant difference in splint removal was detected between group A (acute post injury) and group B (elective postoperative)

TABLE 3: Reasons cited by patients for the removal of hand CPM device

\begin{tabular}{lc}
\hline Reason & Number of patients \\
\hline Prevents ADL & 13 \\
Pain/fingernail problems & 12 \\
Sleep disruption & 10 \\
Cumbersome & 7 \\
Unable to wear at work & 2 \\
Cost (batteries) & 2 \\
Machine breakdown & 2 \\
Swelling & 1 \\
\hline
\end{tabular}

ADL Activities of daily living

$(\mathrm{n}=2)$, intra-articular sepsis $(\mathrm{n}=\mathrm{l})$, tenosynovectomy $(\mathrm{n}=\mathrm{l})$ and Dupytren's contracture (1).

In group A, patients were started on CPM because the complexity of injuries would otherwise prohibit early active physiotherapy. Group B patients were, in general, started on CPM in order to maintain the ROM achieved in the operating room. Group $\mathrm{C}$ patients had unusually resistant hand surgical problems which did not respond to conventional therapy. Since group $\mathrm{C}$ is so diverse it will not be statistically assessed as an individual group and omitted in ROM outcome studies.

Patients were seen either in the emergency room acutely or were referred to the Hand Surgery Clinic for evaluation. The mean age at surgery was $38 \pm 2$ years. There were 22 males and 14 females. Patients were treated with hand CPM for a mean duration of $39 \pm 6$ days and most were compliant (mean daily duration of CPM therapy was $19 \pm 1 \mathrm{~h}$, Table 1 ). The mean total duration of CPM treatment was $741 \pm 84 \mathrm{~h}$ (range 152 to $2160 \mathrm{~h}$ ). The mean follow-up was $32 \pm 3$ months (range seven to 72 months). Patients were off work for a mean of $190 \pm 53$ days (range zero to 1071). Five patients ( $8 \%$ ) were unable to return to their former employment. Nine of the patients $(23 \%)$ had suffered injuries at work and were followed by the Workman's Compensation Board. 
TABLE 4: Patient satisfaction with hand CPM using physician administered visual analogue type questionnaire

\begin{tabular}{lccl}
\hline & Acute (\%) & Elective (\%) & Total (\%) \\
\hline Outcome & $71 \pm 6$ & $66 \pm 6$ & $68 \pm 4$ \\
Function & $70 \pm 6$ & $67 \pm 5$ & $68 \pm 4$ \\
Pain on CPM & $7 \pm 2$ & $23 \pm 5$ & $18 \pm 4$ \\
Satisfaction with CPM & $79 \pm 9$ & $71 \pm 6$ & $73 \pm 5$ \\
\hline
\end{tabular}

No significant difference was detected between the acute post injury (group A) and elective postoperative (group B) groups (ANOVA)

TABLE 5: Range of motion (ROM) outcome (Strickland formula) for patients treated with hand CPM in group $A$ (acute post injury) and group $B$ (elective reconstruction)

\begin{tabular}{|c|c|c|c|}
\hline & $\begin{array}{c}\text { Acute } \\
\text { Group A }\end{array}$ & $\begin{array}{l}\text { Elective } \\
\text { Group B }\end{array}$ & Total \\
\hline Number of patients & 9 & 22 & \\
\hline Number of digits & 16 & 26 & 42 \\
\hline $\begin{array}{l}\text { DIP, PIP range } \\
\text { preoperatively } \\
\text { (degrees) }\end{array}$ & $\mathrm{N} / \mathrm{A}$ & $28 \pm 4$ & $28 \pm 4$ \\
\hline $\begin{array}{l}\text { DIP, PIP range } \\
\text { postoperatively } \\
\text { (degrees) }\end{array}$ & $63 \pm 7$ & $67 \pm 5$ & $66 \pm 7$ \\
\hline
\end{tabular}

There was a significant ( $P \leq 0.05)$ improvement in group $B$ patients postoperatively compared to preoperative ROM (paired $\mathrm{t}$ test)

The CPM device was removed zero to two times per day in 12 patients, three to five times per day in 15 patients and greater than five times per day in four patients (Table 2). Reasons cited by the patient for removal of the CPM unit included: fingernail pain and/or deformity, sleep disruption, awkwardness, prevention of activities of daily living and inability to work (Table 3). No wound breakdowns were observed. No significant difference between overall outcome or ROM was observed between the compliant and noncompliant patients. Overall, there was excellent compliance and a high level of satisfaction among patients with the CPM machine. In order to assess the patients' subjective acceptance of the hand CPM, a visual analogue scale was used. In general, the patients reported that CPM of the hand reduced pain, increased active and passive range of motion and improved overall outcome (Table 4).

In group A, the final ROM (Strickland formula) was $63 \pm 7$ (Table 5). In group B, the mean ROM was $28 \pm 4$ preoperatively and $67 \pm 5$ postoperatively. In group A, the final TAM was $164 \pm 29$ (Table 6). The mean TAM was $112 \pm 14$ preoperatively in group B and $186 \pm 22$ postoperatively. Overall, results were judged to be excellent in $29 \%$, good in $39 \%$, fair in $26 \%$ and failure in $6 \%$ of cases (Table 7 ).

\section{DISCUSSION}

Traditional management of injured or inflamed joints, bones or tendons included prolonged periods of immobilization. Salter demonstrated that CPM increased periosteal chondrogenesis, augmented extrasynovial tendon healing and improved outcome in intra-articular sepsis. The proposed
TABLE 6: Total active motion (TAM) of patients treated with hand CPM in group A (acute post injury) and group $B$ (elective reconstruction)

\begin{tabular}{lccc}
\hline & $\begin{array}{c}\text { Acute } \\
\text { Group A }\end{array}$ & $\begin{array}{c}\text { Elective } \\
\text { Group B }\end{array}$ & Total \\
\hline Number of digits & 16 & 26 & 42 \\
TAM preoperatively & N/A & $112 \pm 14$ & $112 \pm 14$ \\
TAM postoperatively & $164 \pm 29$ & $186 \pm 22$ & $167 \pm 25$ \\
\hline
\end{tabular}

There was a significant $(P<0.05)$ improvement in group $B$ patients postoperatively compared to preoperative ROM (paired t test)

TABLE 7: Subjective assessment of overall outcome by patient and surgeon (in parentheses) in patients treated with hand CPM in group A (acute post injury) and group $B$ (elective reconstruction)

\begin{tabular}{lcccc}
\hline Outcome & $\begin{array}{c}\text { Group A } \\
\text { Acute }\end{array}$ & $\begin{array}{c}\text { Group B } \\
\text { Elective }\end{array}$ & Total & Percentage \\
\hline Excellent & $4(4)$ & $5(5)$ & $9(9)$ & 29 \\
Good & $4(1)$ & $11(11)$ & $15(12)$ & 39 \\
Fair & $1(3)$ & $4(4)$ & $5(7)$ & 26 \\
Poor & 0 & 0 & 0 & 0 \\
Failure & 0 & $2(2)$ & $2(2)$ & 6 \\
\hline
\end{tabular}

No significant difference in outcome between outcome in the two groups or between the assessment by patient and surgeon was detected (two-way ANOVA)

mechanism for these beneficial effects includes the prevention of synovial adhesions, increased diffusion of nutrients via the increased synovial fluid uptake, stimulation of living chondrocytes, and clearance of lysozymal enzymes and purulent exudate from the synovial cavity (1-5). A wide variety of applications have been evaluated. The most impressive clinical results have emerged using CPM for postoperative rehabilitation after intra-articular fractures (6), knee ligament repairs $(7)$, osteotomies of the hip or knee $(19,20)$ and elbow $(8,9)$ and temporomandibular joint surgery $(10,11)$.

Ketchum (14) initially reported experience with the electrically driven hand splint in 1972. This device was developed to extend passively the fingers for durations of 6 to $8 \mathrm{~h}$ per day in patients who had suffered extensor tendon injuries which had been surgically repaired. The use of this creative prototype was later evaluated in 426 stiff joints in 142 patients (15) and found to improve significantly the TAM and total passive motion.

Clearly, the indications for the use of hand CPM are evolving. A summary of the available literature is presented in Table 8. Prosser et al (21) studied the use of CPM in 22 patients who had suffered hand injuries including fractures, joint and crush injuries, and septic arthritis. The authors found that CPM treatment was generally effective; however the beneficial effects plateaued (ROM) approximately seven days after commencing. It was concluded that CPM can be a useful adjunct to hand therapy in a wide variety of hand conditions with restricted ROM. Other authors have recommended hand CPM for the following: patients in whom pain and edema persists longer than expected post injury or post- 
TABLE 8: Indications for hand CPM

\begin{tabular}{ll}
\hline $\begin{array}{l}\text { Acute } \\
\text { Burns }\end{array}$ & Author (reference) \\
$\begin{array}{l}\text { Intra-articular sepsis, fractures, } \\
\text { crush injuries }\end{array}$ & $\begin{array}{l}\text { Kealey, } 1987(12) \\
\text { Prosser, } 1987(24)\end{array}$ \\
Flexor tendon repairs & \\
Extensor tendon repairs & Gelberman, $1990(16)$ \\
Joint injuries & Bunker, $1990(17)$ \\
& Ketchum, $1972(15)$ \\
Reconstructive & Prosser, $1989(21)$ \\
Tenolysis and capsulotomy & Cannon, $1989(22)$ \\
Rheumatoid and implant surgery & Scirven, $1987(25)$ \\
Reflex sympathetic dystrophy & Merritt, $1987(32)$ \\
& Gelberman and \\
& Dimick, $1987(33)$ \\
\hline
\end{tabular}

operatively; patients in whom passive range of motion is not full preoperatively; patients in whom an extensive tenolysis is required; and in fearful patients (22).

A recent survey of therapists at 100 burn centres revealed that $44 \%$ of respondents (response rate $54 \%$ ) used hand CPM in burn patients (23). The hand CPM units used by these therapists included the Kintec, Stryker, Richards, Chattanooga, Toronto Medical Corporation Mobilimb, Therakinetics, Danniger and Invacare models. Covey et al (12) reported the use of hand CPM (Sutter 5000) in 10 burn patients and suggested that indications for the use of hand CPM include extensive burn involvement of multiple kinetic areas, patients who are unable to participate actively in rehabilitation and in patients in whom excessive pain or anxiety precludes normal hand therapy $(12,24)$.

Scirven et al (25) reviewed the use of hand CPM in 120 patients for a variety of indications including joint release, tendon repair, tenolysis, Dupytren's contracture release and PIP or MCP joint replacement. They used three CPM machines, (Sutter, Zimmer and Richards) and found a dramatic relief of postoperative pain and edema. Evidence had accumulated in experimental and clinical studies that indicates that intermittent passive motion is beneficial to functional outcome of repaired flexor tendons (18,26-30). Gelberman (16) found that the use of hand CPM following flexor tendon repairs resulted in significantly improved ROM compared to traditional early passive motion treatment. A subsequent uncontrolled study of hand CPM use in Verdan zone II flexor tendon injuries produced good or excellent results in $86 \%$ of patients (17). McCarthy et al (31) found that chicken feet treated with continuous passive motion as an adjunct to tenolysis had an overall reduction in the ROM compared to animals which were treated with restricted activity.

Several reports of hand CPM use in rheumatoid arthritis hand reconstruction have emerged $(32,33)$. To date, this work is preliminary and inconclusive; however, it appears that hand CPM may aid in the reduction of joint motion after arthroplasty and in rehabilitation following synovectomy and soft tissue reconstruction.

In the present review we describe the use of hand CPM in acute and elective reconstructive settings. It appears from the subjective evaluations that the CPM was well accepted by patients, principally because it relieved pain. Various regimens for use of hand CPM have been described. An early application of the machine in the initial $24 \mathrm{~h}$ postoperatively is important to improve patient's acceptance. In the present series, it is noteworthy that there did not appear to be a significant difference in outcome between the patients who were very compliant (used CPM machines $23 \mathrm{~h}$ per day or longer) and those who were less compliant and used their machines for shorter durations. The patient's progress and state of wound healing are the most important determinants of the duration of CPM required. Each patient's care should be individualized based on close hand therapy follow-up. If the patient's pain and swelling persist, then CPM may be continued for several weeks. In crush injuries and other salvage situations, CPM may be continued for several months, often at the request of the patient. When the range of motion off CPM equals that on CPM, and when postoperative pain and edema are resolving, use of the machine may be discontinued.

Since Ketchum's earliest description of the electric hand splint and the developmental work done by Toronto Medical Corporation, a number of models of hand CPM have become available. Cannon et al (22) reported use of the Sutter model hand CPM and has found that the ability to adjust the force, speed and arc of motion are important features. The problem with all hand CPM units available, however, is that multiple joints will be affected by a single deforming force leaving the more damaged joints to move the least. The Sutter CPM 5000 unit has been used for capsulectomy of the PIP joint (28) flexor tendon repairs (29) and for hand burns (12). In a review of the hand therapy units in 100 burn units, the Sutter was the most commonly used for burn rehabilitation (23). Bunker has noted difficulty in obtaining full extension of the PIP joint, adequate mobilization of the DIP joint and optimal adhesion of the CPM unit to the fingertips in flexor tendon repairs (17). Despite this, excellent results were obtained.

In this review, hand CPM appears to provide excellent pain relief and improved results in salvage situations. The disadvantages include the requirement for active ROM exercises by a trained hand therapist, and the cost of the unit. The theoretical problem with hand CPM today, which has not been answered by any of the existing units, includes the deficiency of tendon excursion through the tendon sheaths of the hand. As well, in the three joint digital skeletal system, one joint may not move through a complete range of movement despite maximal motion of the machine. Inadequate tendon excursion in the hand with the CPM machine pushes and does not pull the flexor tendon, and hence the tendon may become adherent to the surrounding sheath lining. Bunker (17), for example, found the relative lack of movement at the DIP joint to be a problem. This problem could be addressed by adding an electrical nerve stimulation device which could stimulate the profundus muscle synchronously with flexion 
excursion of the hand CPM device. Other important unanswered questions persist. What are the best indications for use of hand CPM? What is the optimal duration and frequency of CPM use? What are the requirements for active hand therapy when hand CPM is used?

\section{CONCLUSIONS}

In certain salvage situations, CPM of the hand appears to be effective in providing a painless range of motion in otherwise stiff and painful digits. CPM of the hand does not appear to provide adequate excursion of the flexor tendons and

\section{REFERENCES}

1. Salter RB. Regeneration of articular cartilage through continuous passive motion: past, present and future. In: Straub R, Wilson PD, eds. Clinical Trends in Orthopedics. New York: Thieme-Stratton Inc, 1982:101-7.

2. Salter RB, Simmonds DF, Malcolm BW, et al. The biological effect of continuous passive motion on the healing of full-thickness defects in articular cartilage. J Bone Joint Surg 1980;62A:1232-51.

3. Salter RB, Bell RS, Keeley FW. The protective effect of continuous passive motion on living articular cartilage in acute septal arthritis: An experimental investigation in the rabbit. Clin Orthop Rel Res 1981;159:223-47.

4. O'Driscoll SW, Salter RB. The induction of neochondrogenesis in free periosteal autografts under the influence of continuous passive motion: An experimental investigation in the rabbit. J Bone Joint Surg 1984;66A:1248-57.

5. Van Royen BJ, O'Driscoll SW, Wouter, Salter, RB. A comparison of the effects of immobilization and continuous passive motion on surgical wound healing in mature rabbits. Plast Reconstr Surg 1986; 18:360-6.

6. Salter RB, Hamilton HW, Wedge JH. Clinical application of basic research on continuous passive motion for disorders and injuries of synovial joints: A preliminary report of a feasibility study. J Ortho Res 1984;1:325-42.

7. Noyes FR, Mangine RE, Barber S. Early knee motion after open and arthroscopic anterior cruciate ligament reconstruction. Am J Sports Med 1987;15:149-60.

8. Green WB. Use of continuous passive slow motion in the postoperative rehabilitation of difficult pediatric knee and elbow problems. J Ped Ortho 1983;3:419-23.

9. Breen TF, Gelberman RH, Acherman, GN. Elbow flexion contractures: Treatment by anterior release and continuous passive motion. J Hand Surg 1988;13B:286-7.

10. Sebastian MH, Moffett BC. The effects of continuous passive motion on the temporomandibular joint after surgery. Oral Surg Oral Med Oral Pathol 1989;67:644-53.

11. Poremba EP, Moffett BC. The effects of continuous passive motion on the temporomandibular joint after surgery. Part 1. Appliance design and fabrication. Oral Surg Oral Med Oral Pathol 1989;67:490-8.

12. Covey MH, Dutcher K, Marvin JA, Heimbach DM. Efficacy of continuous passive motion (XCPM) devices with hand burns. J Burn Care Rehab 1988;9:397-400.

13. Morris JS. Continuous passive motion in postoperative rehabilitation of the hand-A prospective study. Proc Can Ortho Assoc 1986;42:11.

14. Ketchum LD, Clark LC, Robinson DW, Masters FW. A new electric hand splint. J Bone Joint Surg (Am) 1972;54:902-8. hence should be combined with active hand therapy. The patient must be intermittently monitored while on hand CPM to avoid the prolonged lack of progression at a certain joint which may be ameliorated by splint adjustment. (Therefore, close hand therapy follow-up will both provide active ROM exercises and splint surveillance). High compliance was a consistent feature of hand CPM. This may be due to the fact that the device actually relieved pain in the vast majority of patients. For a variety of difficult hand surgical problems good or excellent results were obtained in $68 \%$ of patients treated with postoperative hand CPM.

15. Ketchum LD, Hibbard A, Hassanein KM. Follow-up report on the electrically driven hand splint. J Hand Surg 1979;4:474-81.

16. Gelberman RH, Nunley JA, Osterman AL, Breen TF, Dimick, MP, Woo SLY. Influences of the protected passive mobilization interval on flexor tendon healing. A prospective randomized clinical study. J Hand Surg. (In press)

17. Bunker TD, Potter B, Barton NJ. Continuous passive motion following flexor tendon repair. J Hand Surg 1989;14:406-11

18. Strickland JW, Glogovac SV. Digital function following flexor tendon repair in zone II: A comparison of immobilization and controlled passive motion techniques. J Hand Surg 1980; 5:537-43.

19. Fanton GS. Rehabilitation of the knee after anterior cruciate ligament surgery. Phys Med Rehab 1987;1:639-48.

20. Coutts RD. Symposium: The use of continuous passive motion in the rehabilitation of orthopedic problems. Contemp Ortho 1988;16:75-103.

21. Prosser R. The value of continuous passive motion in hand therapy. World Congress Physical Ther 1987;10:884-8.

22. Cannon NM. Enhancing flexor tendon glide through tenolysis and hand therapy. J Hand Ther 1989;16:122-37.

23. Johnson CL. Editorial. J Burn Care Rehab 1988;9:396.

24. Kealey GP, Jensen KT. Aggressive approach to physical therapy management of the burned hand. Phys Ther 1988;68:683-5.

25. Scirven T, Bora FW, Osterman AL. The use of continuous passive motion in hand rehabilitation. Am Soc Surg Hand 1987;42:51.

26. Chow JA, Thomas LJ, Dovelle S, Monsivais J, Milnor WH, Jackson, JP. Controlled motion rehabilitation after flexor tendon repair and grafting. A multi-centre study. J Bone Joint Surg 1988;70B:591-5.

27. Chow JA, Thomas LJ, Dovelle S, et al. A combined regimen of controlled motion following flexor tendon repair in no man's land. Plast Reconstr Surg 1987;79:447-55.

28. Werntz JR, Chesher SP, Breidenbach WC, Kleinert HE, Bissonnette MA. A new dynamic splint for postoperative treatment of flexor tendon injury. J Hand Surg 1989;14A:559-66.

29. Gelberman RH, Vandeberg JS, Lundborg GN, Akeson WH. Flexor tendon healing and restoration of the gliding surface. An ultrastructural study in dogs. J Bone Joint Surg 1983;65A:70-80.

30. Gelberman, RH, Botte, MJ, Spiegelman, JJ, Akeson, WH. The excursion and deformation of repaired flexor tendons treated with protected early motion. J Hand Surg 1986;IIA:106-10.

31. McCarthy JA, Lesker PA, Peterson WW, Manske PR. Continuous passive motion as an adjunct therapy for tenolysis. J Hand Surg 1986:11B:88-90.

32. Merritt JL. Advances in orthotics for the patient with rheumatoid arthritis. J Rheumatol 1987;14(Suppl 15):62-7.

33. Gelberman RH, Dimick MP. The biotechnology of hand and wrist implant surgery and rehabilitation. J Rheumatol 1987;14(Suppl 15):53-61. 